\title{
Radioastronomers hammer out an agreement on mobile phones
}

[MUNICH] Radioastronomers have gained a small victory in their battle with the telecommunications satellite operator Iridium over use of an important radiofrequency. But victory comes at a cost: they have had to accept a significant loss in observing time.

Iridium launches its global mobile telephone service next month. It is based on a system of 66 satellites operating both uplinks and downlinks in a single frequency band, adjacent to the 1,612 $\mathrm{MHz}$ band reserved by international law for radioastronomers.

Technical inadequacies in Iridium's system mean that overspill emissions from the downlink will drown out the weak 1,612$\mathrm{MHz}$ signals from deep space (Nature 380, 569; 1996).

While US radioastronomers have reached a time-sharing agreement with Iridium, their European counterparts have fought hard to protect their frequencies. They have won the support of their governments, which have withheld operating licences from Iridium until agreement is reached over acceptable pollution levels.

After six months of acrimonious negotiations, Iridium this week signed an agreement with the European Science Foundation (ESF) on behalf of its associated Committee on Radio Astronomy Frequencies (CRAF). This should keep the $1,612 \mathrm{MHz}$ band clear of interference until next March. The situation should improve after January 2006, the deadline by which Iridium must replace its 66 satellites with an improved non-polluting system.

According to the terms of the agreement, Iridium and radioastronomers will have to work together to develop non-polluting nextgeneration satellites, and to develop technical fixes to reduce the susceptibility of radioastronomy equipment to overspill emissions.

During the next few months Iridium and radioastronomers will have to reach a further agreement on time-sharing during the period between March 1999 and 2006. With both sides determined to keep the lion's share of the time, the battle will be hard fought.

Willem Baan, chairman of the InterUnion Commission on Frequency Allocations for Radioastronomy and Space Science, and director of the Westerbork Observatory in the Netherlands, is worried that the requirements of radioastronomers are more than Iridium will want to concede. He is also unhappy about the spirit of the negotiations so far. "Iridium knew of the radioastronomy problem as early as 1991," he says. "Yet it did little to solve it in the design phase of their system and so now we have a serious problem."

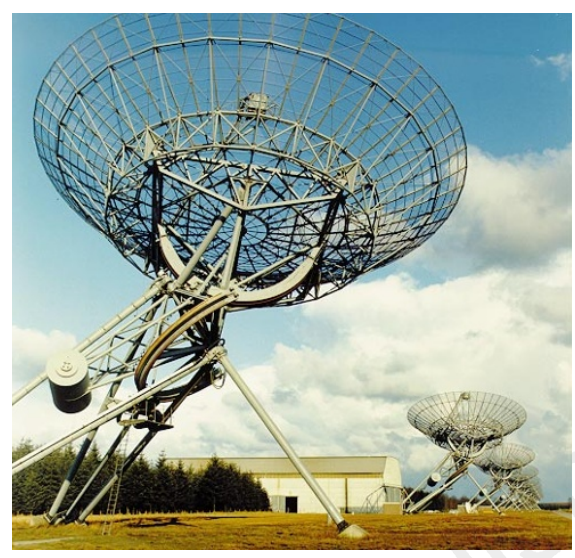

Close call: next March these dishes at Westerbork will begin competing with mobile phones.

He believes that radioastronomers are paying for Iridium's failure to solve its own problems. "It is still not clear that radioastronomers will be able to perform very sensitive observations in the immediate vicinity of the strong main transmission of Iridium," he says. "Other first-generation mobile satellite service systems avoid these problems by using other downlink frequencies."

\section{Industrialist to head UK research councils}

[LONDON] The British government has announced that John Taylor, director of Hewlett-Packard's European research centre in Bristol, will be the new Director General of Research Councils (DGRC). Taylor will take over on 1 January 1999 for a three-year term of office.

Taylor, who is also president-elect of the Institution of Electrical Engineers, has worked for Hewlett-Packard since 1984. His appointment continues a tradition set by the previous, Conservative government of choosing a scientist from industry rather than academia for the job of DGRC. The present incumbent, Sir John Cadogan, was formely with the oil company BP.

Peter Mandelson, newly-appointed Secretary of State for Trade and Industry, and cabinet minister with responsibility for science, said he was "delighted" to see someone of John Taylor's stature as DGRC. "I passionately believe science is the bedrock to economic success," he said last week.

The move underlines the government's commitment to Foresight, an initiative to improve links between science and industry, set up by the previous government to harness science in the service of wealth creation and quality of life. Taylor is

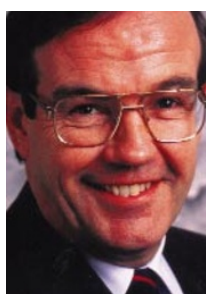

committed to Foresight as chair of the expert panel on information technology and communications.

One of Taylor's responsibilities will be to advise on the next phase of Foresight. Consultation is Taylor: to theme already under way on plans or not to theme? to put more emphasis on using science to enhance quality of life. One suggestion is to reduce the numbers of expert panels and concentrate on getting science to focus on 'themes' such as ageing, crime control and the future of cities.

Taylor has criticized this approach (see Nature 393, 8; 1998), arguing that it is too early in the process to make such a change, particularly as many sectors of industry have yet to fully exploit the wealth-creating potential of better links with science.

Taylor's appointment completes a string of significant changes to the administration of British science, including the arrival of the industrialist Lord (David) Sainsbury in a newly-created junior ministerial post for science (see Nature 394, 511; 1998).

Ehsan Masood 